\title{
Ação do EDTA sobre a camada residual nos terços cervical, médio e apical do canal radicular
}

\author{
Maria de Fátima Malvar Gesteira* \\ Silvio José Albergaria da Silva* \\ Roberto Paulo Correia de Araújo ${ }^{* * *}$ \\ Henrique Lenzi**** \\ Maria Celina B. Siquara da Rocha $a^{* * * *}$
}

\begin{abstract}
Resumo
Concluída a instrumentação, é possível constatar a deposição, na superfície dentinária, de um extrato de material orgânico e inorgânico de aparência amorfa, superfície irregular e granulosa, denominado camada residual. Com o presente estudo, buscou-se analisar, in vitro, através da microscopia eletrônica de varredura, o efeito do EDTA, nas concentrações de 3\%, $5 \%, 10 \%$ e 17\%, na remoção da camada residual e na desobstrução dos túbulos dentinários. Da amostra constituída de 80 dentes, foram selecionados randomicamente 8 unidades para compor o grupo controle negativo (GC1) e 8 para constituir o grupo controle positivo (GC2); os 64 restantes compuseram os 8 grupos experimentais (GExp). Após a instrumentação do canal radicular, foi realizada a irrigação final com as soluções de EDTA em teste. A análise das fotomicrografias com magnitude de 2000X revela que o terço apical apresentou grau de limpeza inferior aos terços cervical e médio.
\end{abstract}

Palavras-chave: Camada residual. EDTA. Preparo do canal.

\section{INTRODUÇÃO}

O preparo do canal radicular é a fase mais importante do tratamento endodôntico (McCOMB; SMITH, 1975; SERPER et al., 2001; SAHLI, 2001; GAMBARINI; LASZKIEWICZ, 2002). Ingle e Beveridge (1985) atribuem à etapa de obturação do canal maior responsabilidade pelo insucesso do trata- mento endodôntico, ressalvando, entretanto, a necessidade de se atentar para as condições das paredes do canal após a instrumentação, uma vez que é sobre elas que a obturação será realizada.

Stewart (1998) afirmou que a limpeza e a modelagem do canal são elementos essenciais ao sucesso do tratamento endodôntico. Sen,

\footnotetext{
* Mestre em Clínicas Odontológicas. Professora de Endodontia Clínica e Laboratorial. UFBA. Rua Aloísio de Carvalho n.14 ap. 1302,Vitória

** Livre Docente em Endodontia. Mestre em Endodontia. Professor de Endodontia Clínica e Laboratorial. UFBA.

${ }^{* * *}$ Livre Docente em Odontologia. Professor de Bioquímica. UFBA. UCSal

${ }^{* * * *}$ Chefe do Departamento de Patologia do Instituto Oswaldo Cruz. FIOCRUZ, Ministério da Saúde. Rio de Janeiro.

${ }^{* * * *}$ Doutora em Odontopediatria. Professora de Odontopediatria. UFBA.
} 
Wesselink e Türkün (1995) observam que o êxito do tratamento depende do método e da qualidade da instrumentação, da irrigação, da desinfecção e da obturação tridimensional do canal radicular. Acrescentaram, ainda, que o objetivo da instrumentação e da irrigação é se alcançar um canal limpo e livre de resíduos para a obturação, contudo as técnicas existentes não são capazes de assegurar a limpeza de todo o sistema de canais, principalmente os canais irregulares e/ou curvos.

Soluções irrigadoras têm sido usadas durante e após a instrumentação para aumentar a eficiência dos instrumentos endodônticos e para retirar resíduos. A eficácia das soluçôes irrigadoras é dependente não apenas da natureza química da solução, mas também da quantidade e da temperatura, do tempo de contato, da profundidade de penetração da agulha irrigadora, da tensão superficial da solução irrigadora e do tempo de validade do produto (INGLE; BEVERIDGE, 1985).

De acordo com Paiva e Antoniazzi (1988), a ação mecânica dos instrumentos endodônticos sobre a parede dentinária libera raspas de dentina e resíduos orgânicos, que, misturados às substâncias químicas, formam uma massa pastosa que tende a impregnar a superfície dentinária, sedimentando-se com mais intensidade na porção apical do canal. Esta camada residual dificulta o processo de limpeza pelo comprometimento da ação de detergência, que necessita, para a sua eficácia, íntimo contato com os substratos lipoprotéicos. Admitiram, também, que, com a presença de germes, a camada residual é um obstáculo à desinfecção, comprometendo o contato dos microrganismos com a fração anti-séptica da substância química. Justificam ainda, que a maior concentração da camada residual na região apical decorre do "efeito pilão" da instrumentação e do menor diâmetro desta regiāo, não existindo, portanto, espaço suficiente para que a substância química auxiliar atue na interface instrumento/parede do canal.

Esta camada é um filme de matéria orgânica onde se incrustam partículas minerais agregadas às substâncias químicas auxiliares utilizadas. Depositada na superfície dentinária, a ca- mada residual contém produtos da decomposição do colágeno, podendo conter, ou não, sangue e microrganismos, na dependência da natureza do conteúdo do canal. Tem a espessura de $1 \mu \mathrm{m}$ a $5 \mu \mathrm{m}$. Pode também estar localizada no interior dos túbulos dentinários, até uma profundidade de $40 \mathrm{~mm}$, constituindo-se praticamente de resíduos de dentina. Este material, denominado freqüentemente de camada residual, é também conhecido como lama dentinária, barro dentinário ou smear layer. Possui a aparência amorfa, irregular e granulosa quando examinada ao microscópio eletrônico de varredura (MADER, BAUMGARTNER; PETERS,1984; PAIVA; ANTONIAZZI, 1988; SEM; WESSELINK; TÜRKÜN, 1995; LOPES et al., 1996; SIQUEIRA Jr., 1997; O'CONNELL et al., 2000; SAHLI, 2001).

Sen, Wesselink e Türkün (1995), em extensa revisão de literatura, ratificaram que a camada residual não é uma barreira intransponível às bactérias; ela apenas retarda sua ação. Tal pressuposto reafirma a importância da ação dos desinfetantes enquanto agentes auxiliares do preparo químico-mecânico ou como medicação intracanal. Ao consideram que a camada residual, quando não é eliminada, pode lentamente se desintegrar e dissolver, ou ser removida por meio de produtos bacterianos, entre os quais os ácidos e as enzimas, os autores se referem também às diversas técnicas e soluções que têm sido usadas para remover a camada residual. Afirmam que, embora o hipoclorito de sódio possua elevada ação solvente, ele não é capaz de remover a camada residual, daí recomendarem o uso seqüencial das soluções de hipoclorito de sódio e EDTA para sua remoção.

Fraser (1974) demonstrou que o EDTA, quando aplicado diretamente na superfície do canal por 15 minutos, provocou amolecimento da dentina do canal radicular até uma profundidade limitada nos terços cervical e médio do canal, enquanto a dentina do terço apical permaneceu intocável, demonstrando o amolecimento da dentina nas porçôes mais amplas do canal, o mesmo não acontecendo nas estreitas porçôes apicais. Resultado semelhante foi obtido quando, comparativamente, maiores volu- 
mes do agente quelante foram aplicados diretamente na superfície do canal radicular. Observou que o EDTA, como substância auxiliar do preparo químico-mecânico, não apresentou uma contribuição direta ao alargamento da porção apical do canal, porém, indiretamente, agiu sobre os terços cervicais e médios, provendo mais espaço para os instrumentos endodônticos atuarem com maior eficiência no terço apical.

Para testar a eficiência da limpeza durante a instrumentação empregando $1 \mathrm{ml}$ de hipoclorito de sódio a 5,25\% entre cada instrumento e a irrigação final com $20 \mathrm{ml}$ de várias soluções ou combinações de soluções (soro fisiológico; hipoclorito de sódio a 5,25\%; EDTA a $17 \%$ em pH 7.7; EDTA a 8,5\% em pH 7.7; e ácido cítrico a $25 \%$ em $\mathrm{pH}$ 1.6), Yamada e colaboradores (1983) utilizaram 40 dentes recémextraídos, instrumentados até a lima K\#50 e divididos em sete grupos experimentais e um grupo controle. Os resultados obtidos, após a análise das superfícies, no microscópio eletrônico de varredura demonstraram que a irrigação final com $10 \mathrm{ml}$ de EDTA a $17 \%$ em pH 7.7, seguido por $10 \mathrm{ml}$ de hipoclorito de sódio a $5,25 \%$ foi mais efetiva. O uso da solução de EDTA a $8,5 \%$ seguida do hipoclorito de sódio removeu efetivamente a camada residual, entretanto permaneceram mais restos superficiais espalhados do que no grupo EDTA 17\%/hipoclorito de sódio. Os resultados demonstraram a necessidade da atividade química combinada dos irrigantes ao lado de um elevado volume de irrigação após o preparo químico-mecânico. A remoção da camada residual foi espe-cialmente notada nas porções coronárias e médias do canal. Os pesquisadores observaram que os agentes quelantes usados isoladamente deixaram variável quantidade de resíduos superficiais ao longo da parede dentinária e, para obter um efeito máximo após o preparo químico-mecânico, é necessário usar quelantes seguidos por um solvente tecidual. Estas associaçôes removeram resíduos e a camada residual mais eficientemente do que todas as outras soluções usadas isoladamente, comprovando que tanto a combinação quanto a sequiência do uso são importantes.

Khouri Diep e Bramante (1997) analisa- ram, através da microscopia eletrônica de varredura, a ação de limpeza dos canais radiculares em função do modo de aplicação do EDTA nos terços apical, médio e cervical. Quanto ao grau de limpeza obtido entre os terços do canal, observaram que, em média, o terço cervical mostrou-se mais limpo do que o médio, e este mais limpo do que o apical. Entretanto não constataram diferenças estatisticamente significativas entre os dois primeiros $(\mathrm{p}<0,05)$, isso acontecendo, porém, entre o cervicomedial e o apical.

Verdelis e colaboradores (1999) investigaram a ação do EDTA a $15 \%$ em pH neutro e o gel RCPrep nos terços cervical, médio e apical. Concluído o preparo químico-mecânico, os espécimes foram tratados com as substâncias supracitadas e a analisados através de microscopia e espectrometria atômica. Os resultados demonstraram que o EDTA neutro removeu a camada residual e provocou elevada descalcificação na superfície dentinária nas porçôes cervicais e médias, enquanto o mesmo não aconteceu com o RCPrep. Consideraram também que a dentina apical é mais calcificada do que a dentina radicular nas porçôes cervical e média. Disso resulta que a descalcificação pelo EDTA neutro não se baseia apenas na quelação do cálcio, mas que a porção orgânica da dentina ocupa um papel crítico durante o processo de descalcificação.

M. F. Z. Scelza, Antoniazzi e P. Scelza (2000) determinaram in vitro o grau de remoção de restos e camada residual de canais radiculares após a irrigação final, durante 4 minutos, em três grupos: com $10 \mathrm{ml}$ de hipoclorito de sódio a $1 \%+10 \mathrm{ml}$ de $19 \%$ de ácido cítrico $+10 \mathrm{ml}$ de água destilada no grupo 1; com 15 $\mathrm{ml}$ de $0,5 \%$ de hipoclorito de sódio $+15 \mathrm{ml} \mathrm{de}$ EDTA-T no grupo 2; e com $10 \mathrm{ml}$ de $5 \%$ de hipoclorito de sódio $+10 \mathrm{ml}$ de $3 \%$ de $\mathrm{H}_{2} \mathrm{O}_{2}+$ $10 \mathrm{ml}$ de $\mathrm{NaOCl}$ a $5 \%$ no grupo 3 . Fotomicrografias obtidas por meio do microscópio eletrônico de varredura foram avaliadas de acordo com o número de túbulos dentinários abertos por três observadores. O mais elevado número de túbulos visíveis nos três grupos ocorreu no terço cervical, seguido pelos terços médio e apical. Não foram encontradas diferenças 
estatisticamente significativas entre os grupos 1 e 2 quando os terços foram comparados entre si. Os grupos 1 e 2 tiveram túbulos dentinários significativamente mais visíveis do que o grupo 3.

Com o presente estudo buscou-se analisar, in vitro, através da microscopia eletrônica de varredura, o efeito do EDTA, nas concentrações de 3\%, 5\%, 10\% e 17\%, na remoção da camada residual e na desobstrução dos túbulos dentinários, nos terços cervical, médio e apical dos canais radiculares.

\section{MATERIAL E MÉTODO}

Foram usados 80 dentes unirradiculares, incisivos e caninos superiores, de humanos, armazenados em recipiente contendo solução de timol a $0,1 \%$. Após serem lavados em água, os dentes foram secos com jato de ar e mantidos em soro fisiológico para reidratação, a $37^{\circ} \mathrm{C}$, em estufa bacteriológica, por um período de sete dias. Para a realização do presente estudo, oito dentes foram selecionados randomicamente para compor o grupo controle negativo (GC1) e outros oito para o grupo controle positivo (GC2). Os 64 dentes restantes foram divididos randomicamente em oito grupos experimentais (GExp1, GExp2, GExp3, GExp4, GExp5, GExp6, GExp7, GExp8) de oito unidades cada um, de acordo com a concentração de EDTA a ser avaliada $(3 \%, 5 \%, 10 \%$ e $17 \%)$ e o tempo de permanência do EDTA em contato com a superfície dentinária, ou seja: 1 e 3 minutos. As amostras que constituíram o grupo controle positivo (GC2) e os grupos experimentais receberam tratamento endodôntico com base na técnica preconizada por Paiva e Antoniazzi (1988).

Concluído o preparo químico-mecânico do canal no grupo experimental, procedeu-se à irrigação final com $10 \mathrm{ml}$ da solução de EDTA nas respectivas concentrações e nos diferentes tempos de aplicação, seguida de $10 \mathrm{ml}$ de hipoclorito de sódio e $10 \mathrm{ml}$ de Tergensol. Para o grupo controle negativo (GC1), o procedimento limitou-se à remoção dos resíduos intracanal com uma lima K\#10 e irrigação com 10 ml de Tergensol.

A fim de padronizar o tamanho dos corpos-de-prova, os dentes, após serem retirados do soro fisiológico e secos com jato de ar, foram apreendidos em uma pequena morsa e seccionados a $19 \mathrm{~mm}$, contados a partir do ápice em direção à coroa (FIGURA 1).
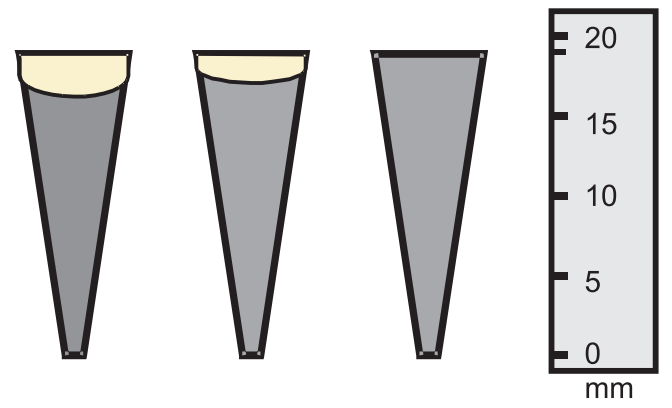
Figura 1 - Modelo de padronização do tamanho
dos dentes

Com o espécime apreendido, horizontalmente, na pequena morsa, procedeu-se à marcação da linha de secção vertical nas faces vestibular e lingual, seguindo-se a abertura de sulcos longitudinais através de discos diamantados. A exigência técnica de se construírem os supracitados sulcos longitudinais antes do preparo químico-mecânico teve por objetivo evitar que o pó dentinário viesse a contaminar o interior do canal radicular depois do tratamento endodôntico.

Após a fixação vertical do espécime na morsa, procedeu-se ao acesso endodôntico e à introdução de uma lima K-file \#15, até que fosse visualizada a ponta deste instrumento no forame apical, subtraído de $1 \mathrm{~mm}$. Foi iniciada a instrumentação com uma lima tipo K-FlexO-file \#20 ou \#25, respeitando-se o limite do comprimento estabelecido para a realização do procedimento endodôntico e limitada a manipulação até a lima K-Flex-O-file \#40, através de limagem circunferencial, e o escalonamento anatômico dos terços coronário e médio com mais quatro instrumentos (\#60) pela técnica proposta por Lopes e colaboradores (1996). 
Processou-se a instrumentação do canal radicular com o auxílio da associação medicamentosa Endo PTC/ solução de Milton (PAIVA; ANTONIAZZI, 1988). A solução de Milton foi renovada a cada troca de instrumento, definindo-se, previamente, o volume total de $10 \mathrm{ml}$ para o preparo químico-mecânico de cada espécime. Findo este processo, procedeuse à lavagem com o restante dos $10 \mathrm{ml}$ da solução de Milton. A irrigação final dos canais radiculares foi realizada, seqüencialmente, com o EDTA, a solução de Milton e o Tergensol, visando ao alcance máximo do terço apical. As soluções de EDTA foram utilizadas de acordo com o estabelecido para os respectivos grupos, ou seja: nas concentraçôes de 3\%, 5\%, 10\% e $17 \%$, e nos tempos de 1 e 3 minutos.

Para cada corpo-de-prova foram destinados, inicialmente, $5 \mathrm{ml}$ de EDTA, mantidos em suspensão durante 30 segundos mediante manipulação mecânica, através de instrumento tipo K-Flex-O-file \#15, em toda a extensão do canal, seguindo-se irrigação complementar com 5 $\mathrm{ml}$ deste fármaco.

Uma vez concluídos os procedimentos endodônticos de preparo químico-mecânico dos canais, os corpos-de-prova foram desidratados pelo álcool etílico a $80 \%, 90 \%$ e $100 \%$. A seguir, as amostras foram secas em estufa bacteriológica a $50^{\circ} \mathrm{C}$ durante uma hora, e embaladas individualmente em papel laminado. Com o auxílio de um cinzel e de um martelo cirúrgico, os espécimes foram clivados em duas hemissecçôes, com base na fissura realizada nos terços cervical, médio e apical da raiz. Em cada amostra, foi registrada com grafite a distância de $6 \mathrm{~mm}$ e $12 \mathrm{~mm}$, a partir do ápice, limitando-se os terços cervical, médio e apical. Concluída esta fase, os espécimes foram novamente envolvidos em papel laminado e acomodados nas suas respectivas caixas até que se processasse a leitura no microscópio eletrônico de varredura.

Fotomicrografias padronizadas, obtidas do microscópio eletrônico de varredura em pressão variável (LEO $435 \mathrm{VP}$ ), pertencente à Funda- ção Oswaldo Cruz-FIOCRUZ, Rio de Janeiro, foram realizadas na hemissecção de cada espécime, tendo-se o cuidado de selecionar aquela com maior integridade física. Dessa forma, foram obtidas 250 fotomicrografias com aumento de 2000X (FIGURA 2).

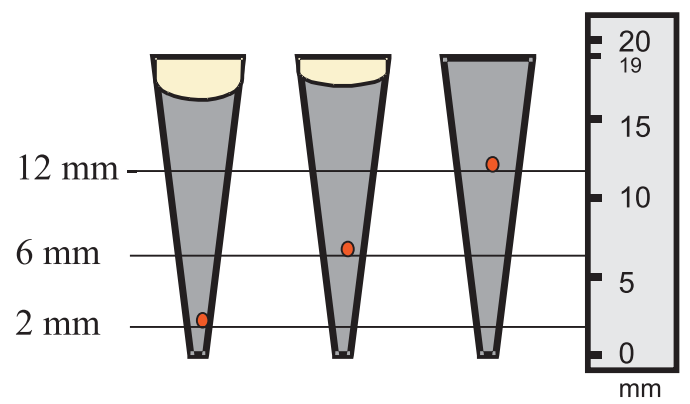

Figura 2 - Pontos aproximados da leitura no microscópio eletrônico de varredura

Para a interpretação das imagens obtidas, foram aplicados os escores: 0 - ausência de camada residual e presença de túbulos dentinários livres de resíduos (FIGURA 3); 1 - presença de camada residual em túbulos dentinários ou smear plugs (FIGURA 4); 2 - presença de camada residual e de túbulos livres de resíduos em áreas de superfície dentinária (FIGURA 5); 3 - presença de camada residual e de túbulos sem contorno nítido em áreas de superfície dentinária (FIGURA 6); 4 - acentuada camada residual na superfície dentinária (FIGURA 7) da escala estabelecida por Rome, Doran e Walker (1985), adaptada ao presente estudo.

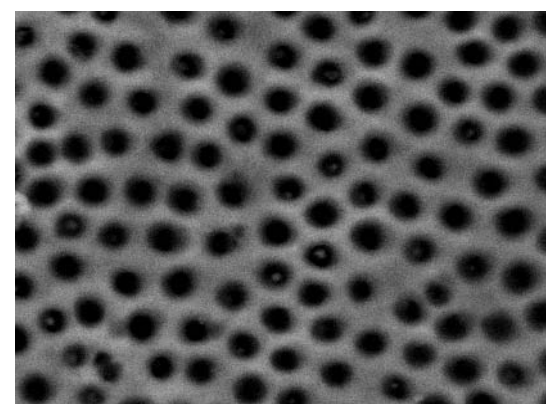

Figura 3 


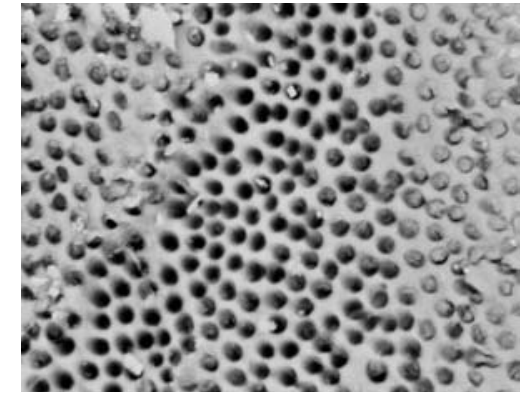

Figura 4

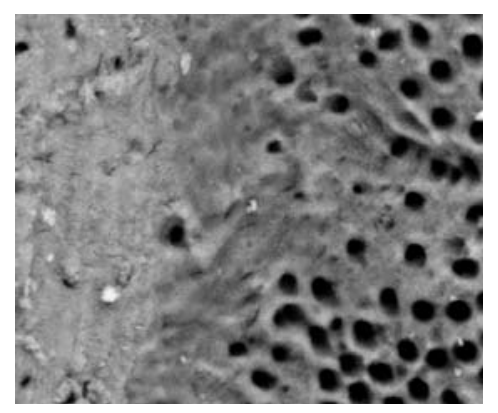

Figura 5

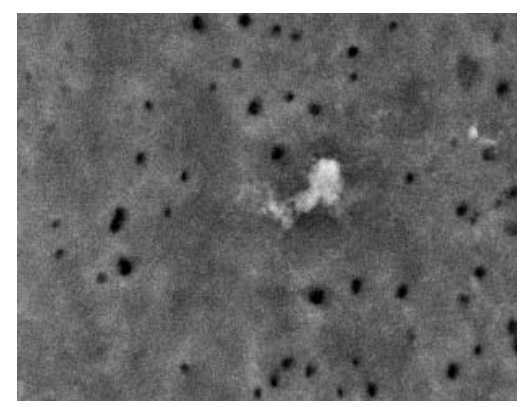

Figura 6

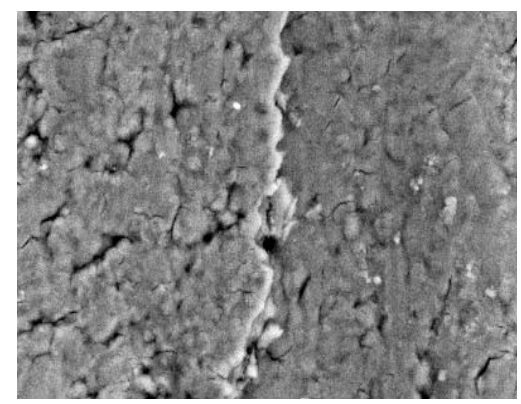

Figura 7

\section{RESULTADOS E DISCUSSÃO}

Diante da complexidade anatômica do sistema de canais e da necessidade de se obter um sistema saneado, diversos pesquisadores vêm desenvolvendo técnicas capazes de modelar o canal sem deformá-lo, buscando ampliar, cada vez mais, o número de superfícies instrumentadas, de forma manual e/ou automatizada, para que o mesmo venha a adquirir progressivamente uma forma cônica, respeitada a posição do forame apical.

Há que se ter especial atenção ao preparo do terço apical do canal, decisivo, por sinal, para o sucesso do tratamento endodôntico. Quando bem instrumentada esta área, as manobras de obturação são mais seguras, diminuindo sobremaneira as chances de insucesso. $\mathrm{O}$ fato de esta região ser alcançada com maior dificuldade pelas substâncias irrigadoras pode resultar no comprometimento da qualidade da limpeza e da desinfecção desejadas. Por outro lado, optar por soluções mais concentradas não é aconselhável, devido à citotoxicidade (PAIVA; ANTONIAZZI, 1988; GARBEROGLIO; BECCE, 1994; SEGURA et al., 1996; SEGURA et al., 1997; KHOURI DIEP; BRAMANTE, 1997; KOULAOUZIDOU et al., 1999).

A opção por criar sulcos longitudinais ao longo da superfície de cada amostra, antes do preparo químico-mecânico do canal, teve por objetivo facilitar a subseqüente clivagem e, principalmente, evitar que a dentina pulverizada, liberada em decorrência do corte com o disco diamantado dupla-face, viesse a penetrar no canal radicular, inviabilizando o uso do espécime.

O comprimento e o diâmetro do canal radicular assim como o volume das soluçôes medicamentosas empregadas influem na eficácia do processo de irrigação. Os canais mais dilatados permitem o acesso da agulha irrigadora às regiões mais apicais, enquanto os canais mais longos dificultam este acesso. Abou-Rass e Piccinino (1982) sugeriram que a irrigação plena do terço apical é de fundamental importância para a remoção de resíduos do canal radicular, daí alertarem para a necessidade de se dilatar os terços médio e cervical. 
Santos (2000), Gavini (1992) e Aun (1990) constataram que o emprego de volumes maiores de soluçôes irrigadoras constitui-se num fator diferencial, uma vez que favorece a remoção de resíduos do interior do canal.

Tendo em conta estes pressupostos, buscouse padronizar a técnica de irrigação, a fim de otimizar a aplicação das soluçôes irrigadoras. Para tanto, os dentes foram seccionados a $19 \mathrm{~mm}$ do ápice e dilatados no comprimento de trabalho até o instrumento K-Flex-O file \#40 com escalonamento até a lima \#60. Estes procedimentos metodológicos tiveram como objetivo permitir que as soluçôes de EDTA e hipoclorito de sódio empregadas pudessem atuar satisfatoriamente, o que seria questionável se não tivesse havido intervenção no comprimento e na dilatação do canal aliados à aplicação da técnica de irrigação para a remoção da camada residual com a utilização de quantidades relevantes destas soluções.

Nas fotomicrografias, constatou-se ocorrência de superfícies não tocadas pelos instrumentos utilizados (FIGURA 8), fenômeno que pode ser atribuído às peculiaridades anatômicas de cada amostra, apesar do rigor na seleção de espécimes uniformes para a realização do presente estudo. Estes achados estão de acordo com os trabalhos de White, Goldman e Lin (1984, 1987), Siqueira Jr. (1997) e Sahli (2001).

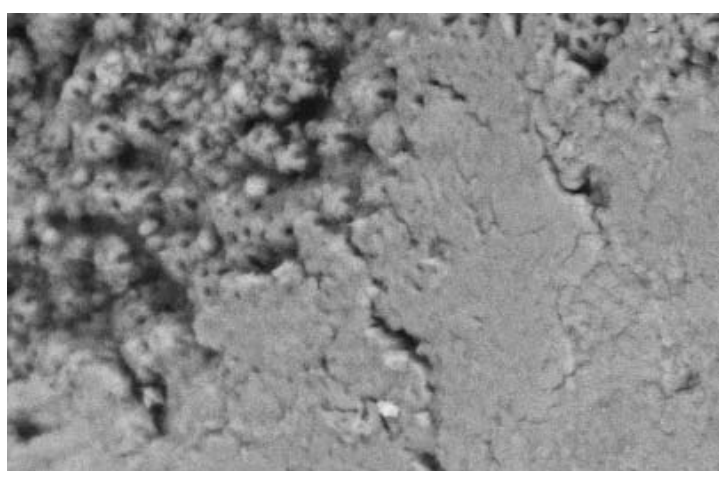

Figura 8 - Fotomicrografia de uma superfície dentinária recoberta pela camada residual, vizinha a uma superfície íntegra, onde são observados inúmeros túbulos dentinários $(\mathrm{Mag}=900 \mathrm{X}, \mathrm{LEO} 425 \mathrm{VP})$
Características próprias da camada residual puderam ser observadas através das fotomicrografias dos espécimes do grupo controle positivo, uma vez que os dentes foram instrumentados com o auxílio do hipoclorito de sódio a 1\% (solução de Milton) e Endo PTC, seguido-se a irrigação final com o Tergensol (FIGURA 9). Tal observação coincide com a de diversos estudos, através dos quais a camada residual foi constatada em espécimes instru-
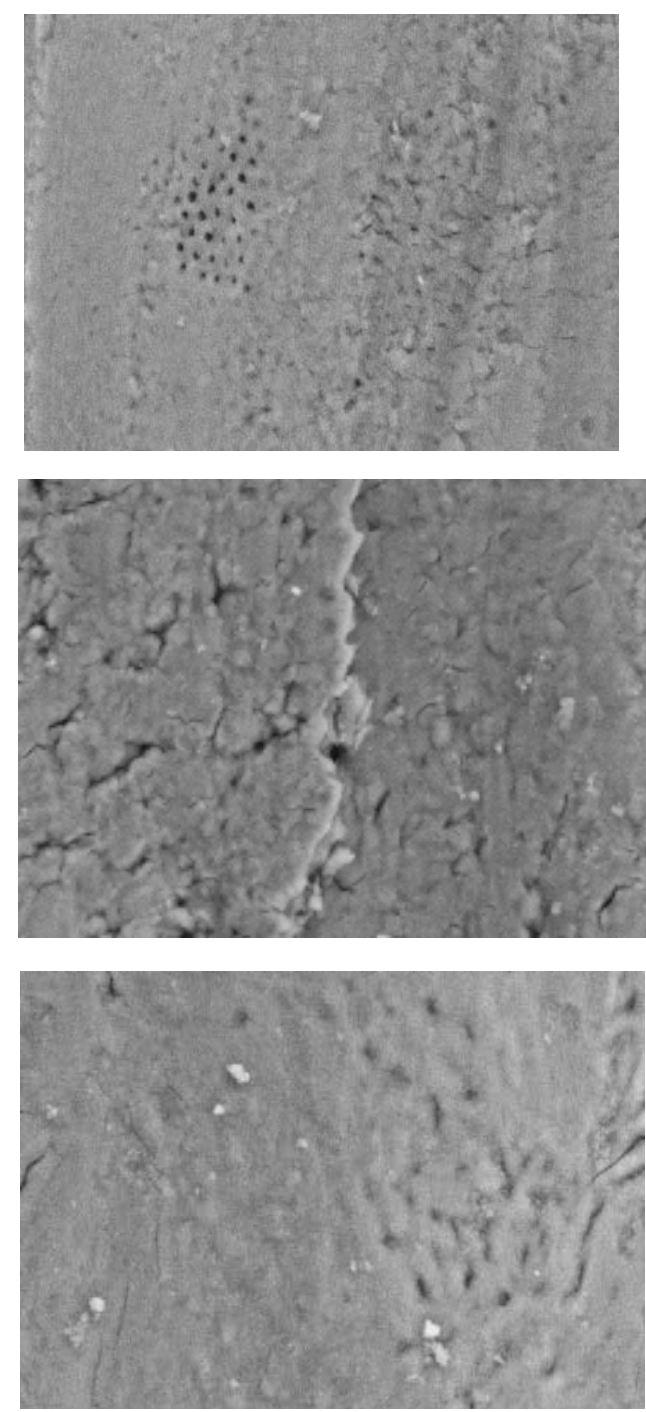

Figura 9 - Fotomicrografias de amostras do grupo controle positivo, onde é notada extensa área de camada residual nos terços cervical (A), médio (B) e apical $(\mathrm{C}),(\mathrm{Mag}=$ 900X, LEO $425 \mathrm{VP})$ 
mentados apenas com o hipoclorito de sódio (SERPER et al., 2001; GAMBARINI; LASZKIEWICZ, 2002; VIEGAS et al., 2002) ou com a associação do hipoclorito de sódio/ Endo PTC (SANTOS, 2000; GAVINI, 1992). As imagens obtidas evidenciam uma camada residual superficial, irregular e amorfa conforme descreve a literatura que trata desta matéria (MADER; BAUMGARTNER; PETERS, 1984; SEM; WESSELINK; TÜRKÜN, 1995; O'CONNELL et al., 2000; TAM; YU, 2000).

Apesar dos cuidados técnicos e do controle de variáveis dependentes, as peculiaridades anatômicas dos corpos-de-prova são fatores limitantes das manobras de limpeza dos terços dos canais que constituíram a amostragem referente aos grupos experimentais. Estas condiçôes justificam a obtenção de médias distintas. Tal possibilidade está fundamentada nas diferenças consideradas estatisticamente significativas, ao se compararem as médias atribuídas ao terço apical com as médias dos terços cervical e médio. Estas constatações estão de acordo com os achados de Goldman e colaboradores (1981); Aktener e Bilkay (1993); Paiva e Antoniazzi (1988); Takeda e colaboradores (1999); Verdelis e colaboradores (1999); O'Connell e colaboradores (2000); Tam e Yu (2000); Gambarini e Laszkiewicz (2002).

Ao observarem que a maior concentração de camada residual é depositada na região apical, Paiva e Antoniazzi (1988) e Tam e Yu (2000) justificaram este fenômeno baseados no "efeito pilão" da instrumentação e no menor diâmetro, próprio desta região, o que implica em falta de espaço suficiente para que as substâncias auxiliares possam atuar na interface instrumento/ paredes do canal.

Ao demonstrar maior amolecimento da dentina pelo EDTA apenas nas porções mais amplas do canal, Fraser (1974) destacou a limitação do acesso às porçôes apicais. Há que se considerar também que a eficácia das soluções irrigadoras, de acordo com Ingle e Beveridge (1985), depende da natureza química, da quantidade empregada, da temperatura, do tempo de contato, da profundidade de penetração da agulha irrigadora, da tensão superficial e da idade da solução irrigadora. Calt e Serper (2000) acrescentaram que a eficiência do EDTA depende também do comprimento do canal, do tempo de aplicação da solução, da dureza da dentina, do $\mathrm{pH}$ e da concentração desta substância.

O estabelecimento do comprimento de 19 mm para as amostras e a opção pelos diâmetros padronizados dos instrumentos $(\# \mathrm{~L} 40=0,40$ $\mathrm{mm}$ ) permitiram que a agulha irrigadora penetrasse até a porção apical do canal e levasse as soluções irrigadoras empregadas neste estudo até estas regiōes. Mesmo assim, a superfície dentinária apresentou-se menos limpa no terço apical, se comparada às áreas correspondentes aos demais terços do canal. Progressivos aumentos nos percentuais dos escores $(0,1$ e 2$)$ indicam melhores índices de limpeza à medida que se aumentou a concentração da solução de EDTA empregada.

Tabela 1- Comparação entre os terços (valores de p)

\begin{tabular}{llc}
\hline Terço & Valor de $\mathrm{p}$ \\
\hline cervical & $\mathrm{x}$ apical & ${ }^{*} 0,000$ \\
médio $\quad \mathrm{x}$ apical & ${ }^{*} 0,018$ \\
médio $\quad \mathrm{x}$ cervical & 0,056 \\
\hline
\end{tabular}

${ }^{*}$ p-valor $<0.05$

Os valores explicitados na Tabela 1 indicam não haver diferenças estatisticamente significativas entre os terços médios e cervical do canal. Estes resultados expressam uma melhor qualidade de limpeza destas regióes, o que pode ser comprovado através das fotomicrografias (FIGURA 10), como observaram os trabalhos de Yamada e colaboradores (1983), White, Goldman e Lin (1984, 1987), Berutti, Marini e Angeretti (1997), Timpawat e Sripanaratanakul (1998), Takeda et al. (1999), Tam e Yu (2000) e O'Connell et al., (2000).

Nos terços cervical e médio das amostras avaliadas, o percentual de limpeza, muito embora tivesse sido superior ao percentual atribuído à porção apical, não resultou em 100\% 
de superfícies isentas de camada residual, em todas as concentrações de EDTA estudadas. Melhores percentuais foram obtidos com a aplicação das soluções de EDTA nas concentrações de $10 \%$ e de $17 \%$, em que pese não ter havido diferenças estatisticamente significativas, uma vez comparados entre si estes resultados. Nestas regiōes, o maior fluxo da solução irrigadora e o maior contato da substância química com a superfície do canal asseguram superfícies mais limpas nestas concentrações.

A presença da camada residual na superfície dentinária retarda a ação da medicação intracanal e das substâncias químicas auxiliares desinfetantes no interior dos túbulos dentinários. Estas reflexões, fundamentadas cientificamente, respaldam, neste momento, a recomendação de remoção da camada residual através dos materiais e técnicas endodônticas avaliados no presente estudo.

\section{CONCLUSÕES}

De acordo com os resultados apresentados no presente trabalho, pode-se concluir, a respeito da remoção da camada residual e da desobstrução dos túbulos dentinários do canal radicular nos terços cervical, médio e apical, que os terços cervical e médio apresentam superfícies mais limpas em relação ao terço apical, independentemente das concentraçôes das soluções de EDTA e dos tempos de aplicação avaliados.
EDTA 10\% - 1' - terço cervical

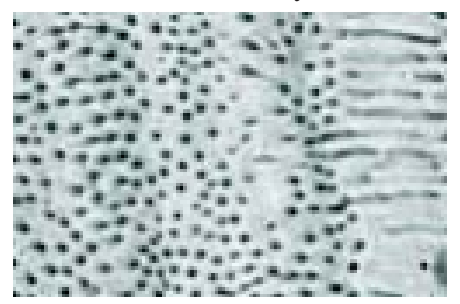

EDTA 17\% - 1' - terço médio

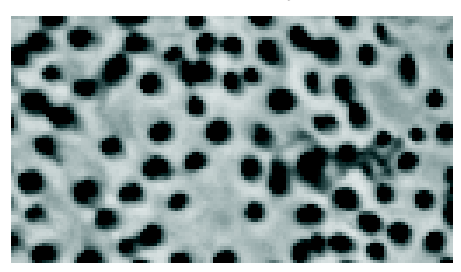

EDTA 10\% - 3' - terço cervical

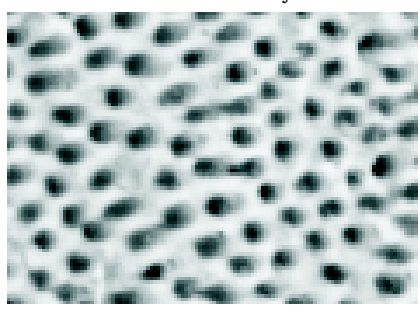

EDTA 17\% - 3'- terço médio

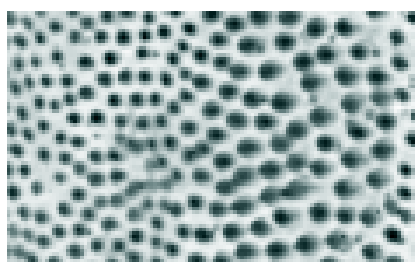

EDTA 10\% - 3`- terco médio

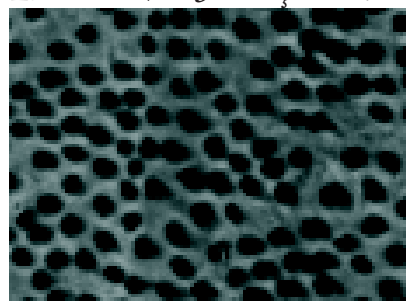

EDTA 17\% - 3' - terço cervical

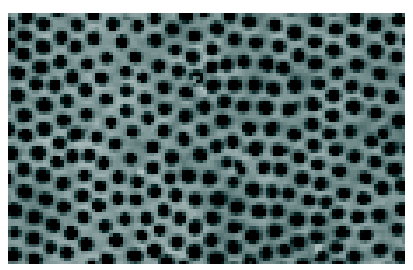

Figura 10 - Fotomicrografias dos terços cervical e médio de espécimes tratadas com diferentes concentrações de EDTA $(\mathrm{Mag}=900 \mathrm{X}, \mathrm{LEO} 425 \mathrm{VP})$

\section{The effect of EDTA in cervical, basal and apical thirds on the removal of the smear layer}

\section{Abstract}

On completion of the instrumentation, it is possible to observe sediments of an organic and inorganic material extract of amorphous aspect, with an irregular and granular surface known as smear layer, on the dentine surface. The aim of this study was to analyze, in vitro, the effect of EDTA in 3\%, 5\%, 10\% and $17 \%$ concentrations on the removal of the smear layer and cleaning of the dentine tubules through scanning electron microscopy. Eight samples out of 80 teeth were randomly selected to compose the negative control set (GC1) and other 8 units to compose the positive control set (GC2). The remaining 64 composed the 8 experimental sets $(G E x p)$. On the instrumentation of the root canal, the final irrigation with the EDTA test 
solutions was performed. The analysis of the photomicrographs at magnitude $2000 X$ revealed that the apical third showed a lower degree of cleaning than the cervical and basal thirds.

Keywords: Smear layer. EDTA. Instrumentation.

\section{REFERÊNCIAS}

ABOU-RASS, M.; PICCININO, M. The effectiveness of four clinical irrigation methods on the removal of root canal debris. Oral Surg. Oral Med. Oral Pathol., St. Louis, v.5, n.3, p.323-328, Sept. 1982.

AKTENER, B. O.; BILKAY, U. Smear layer removal with different concentrations of EDTA-ethylenediamine mixtures. J. Endod., Baltimore, v.19, n.5, p.228-231, May 1993.

AUN, C. E. Análise in vitro através da Microscopia Eletrônica de Varredura, da quantidade de canalículos dentinários livres da camada residual de magma no terço apical do canal radicular, após o preparo químicomecânico, variando-se o instrumento e seu número de uso. 1990. Tese (Livre Docência) - Faculdade de Odontologia, Universidade de São Paulo, São Paulo, 1990.

BERUTTI, E.; MARINI, R.; ANGERETTI, A. Penetration ability of different irrigants into dentinal tubules. J. Endod., Baltimore, v.23, n.12, p.725-727, Dec. 1997.

CALT, S; SERPER, A. Smear layer removal by EGTA. J. Endod., Baltimore, v.26, n.8, p.459-461, Aug. 2000.

FRASER, J. G. Chelating agents: their softening effect on root canal dentin. Oral Surg. Oral Med. Oral Pathol., St. Louis, v.37, n.5, p.803-811,1974.

GAMBARINI, G; LASZKIEWICZ, J. A scanning electron microscopic study of debris and smear layer remaining following use of GT rotary instruments. Int. Endod. J., Oxford, v.35, p.422-427, 2002.

GARBEROGLIO, R.; BECCE, C. Smear layer removal by root canal irrigants: a comparative scanning electron microscopic study. Oral Surg. Oral Med. Oral Pathol., St. Louis, v.78, n.3, p.359-367, Sept. 1994.

GAVINI, G. Avaliação in vitro da limpeza da parede do canal radicular (terço apical), após o preparo químicomecânico, valendo-se da Microscopia Eletrônica de Varredura, tendo como fonte de variação a solução irrigadora e seu volume. 1992. Tese (Mestrado) - Faculdade de Odontologia, Universidade de São Paulo, São Paulo, 1992.
GOLDMAN, L. B. et al. The efficacy of several irrigating solutions for endodontics: a scanning electron microscopic study. Oral Surg. Oral Med. Oral Pathol., St. Louis, v.52, n.2, p.197-204, Aug. 1981.

INGLE, J. I.; BEVERIDGE, E. E. Endodontics. 3rd. ed. Philadelphia: Lea \& Febiger, 1985.

KHOURI DIEP, E; BRAMANTE, C. Efeito do modo de aplicação do EDTA na limpeza das paredes dos canais radiculares. R. FOB., Bauru, v.5, n.1/2, p.1-7, jan./jun. 1997.

KOUlaOUZIDOU, E. A. et al. Cytotoxic effects of different concentrations of neutral and alkaline EDTA solutions used as root canal irrigants. J. Endod., Baltimore, v.25, n.1, p.21-23, Jan. 1999.

LOPES, H. P. et al. Mechanical stirring of smear layer removal: influence of the chelating agent (EDTA). Braz. Endod. J., Goiânia, v.1, n.1, p.52-55, abr. 1996.

MADER, C. L; BAUMGARTNER, J. C; PETERS, D. D. Scanning electron microscope investigation of the smeared layer on root canal walls. J. Endod., Baltimore, v.10, n.10, p.477-483, Oct. 1984.

McCOMB, D; SMITH, D. C. A preliminary scanning electron microscopic study of root canals after endodontic procedures. J. Endod., Baltimore, v.1, n.7, p.238-242, July 1975 .

O'CONNELL, M. S. et al. A comparative study of smear layer removal using different salts of EDTA. J. Endod., Baltimore, v.26, n.12, p.739-743, Dec. 2000.

PAIVA, J. G; ANTONIAZZI, J. H. Endodontia: bases para a prática clínica. 2.ed. São Paulo: Artes Médicas, 1988.

ROME, W. J.; DORAN, J. E.; WALKER, W. A. The effectiveness of gly-oxide and sodium hypochlorite in preventing smear layer formation. J. Endod., Baltimore, v.11, n.7, p.281-288, July 1985.

SAHLI, C. C. Preparación de los conductos radiculares. In: SAHLI, C. C.; AGUADÉ, E. B. Endodontia: técnicas clínicas e bases científicas. Barcelona: Masson, 2001. 
SANTOS, F. L. H.V. Eficácia da remoção in vitro do creme Endo PTC após irrigação final, utilizando espectrômetro de massas na detecçáo de resíduos de Carbowax. 2000. Tese (Doutorado) - Faculdade de Odontologia, Universidade de São Paulo, São Paulo, 2000 .

SCELZA, M. F.Z.; ANTONIAZZI, J. H.; SCELZA, P. Efficacy of final irrigation: a scanning electron microscopic evaluation. J. Endod., Baltimore, v.26, n.6, p.355-358, June 2000 .

SEGURA, J. J. et al. The disodium salt of EDTA inhibits the binding of vasoactive intestinal peptide to macrophage membrane: endodontic implications. J. Endod., Baltimore, v.22, n.7, p.337-340, July 1996.

SEGURA, J. J. et al. EDTA inhibits in vitro substrate adherence capacity of macrophages: endodontic implications. J. Endod., Baltimore, v.23, n.4, p.205208, Apr. 1997.

SEN, B. H.; WESSELINK, P. R.; TÜRKÜN, M. The smear layer: a phenomenon in root canal therapy. Int. Endod. J., Oxford, v.28, n.3, p.141-148, May 1995.

SERPER, A. et al. Comparison of the cytotoxic effects and smear layer removing capacity of oxidative potential water, $\mathrm{NaOCl}$ and EDTA. J. Oral Sci., Tokyo, v.43, n.4, p.233-238, Oct. 2001.

SIQUEIRA JR., J. F. Tratamento das infecçóes endodônticas. Rio de Janeiro: Medsi, 1997.

STEWART, G. A scanning electron microscopic study of the cleansing effectiveness of three irrigating modalities on the tubular structure of dentin. J. Endod., Baltimore, v.24, n.7, p.485-486, July 1998 .
TAKEDA, F. H. et al. A comparative study of the removal of smear layer by three endodontic irrigants and two types of laser. Int. Endod. J., Oxford, v.32, n.1, p.3239, Jan. 1999.

TAM, A.; YU, D. C. An evaluation of the effectiveness of two canal lubricants in removing smear layer. Compend. Contin. Educ. Dent., Jamesburg, v.21, n.11, p.967-972, Nov. 2000.

TIMPAWAT, S.; SRIPANARATANAKUL, S. Apical sealing ability of glass ionomer sealer with and without smear layer. J. Endod., Baltimore, v.24, n.5, p.343-345, May 1998.

VERDELIS, K. et al. Effect of chelating agents on the molecular composition and extent of decalcification at cervical, middle and apical root dentin locations. Endod. Dent. Traumatol., Copenhagen, v.15, n.4, p.164-170, Aug. 1999.

VIEGAS, A. P. K. et al. MEV da parede de dentina frente ao uso do hipoclorito de sódio isolado, associado ao EDTA ou ao Glyde File Prep. JBE, Curitiba, v.3, n.11, p.293-299, 2002.

WHITE, R. R.; GOLDMAN, M.; LIN, P. S. The influence of the smeared layer upon dentinal tubule penetration by plastic filling materials. J. Endod., Baltimore, v.10, n.12, p.558-562, Dec. 1984.

WHITE, R. R.; GOLDMAN, M.; LIN, P. S. The influence of the smeared layer upon dentinal tubule penetration by endodontic filling materials: part II. J. Endod., Baltimore, v.13, n.8, p.369-374, Aug. 1987.

YAMADA, R. S. et al. A scanning electron microscopic comparison of high volume final flush with several irrigating solutions: part 3. J. Endod., Baltimore, v.9, n.4, p.137-142, Apr. 1983. 